\title{
Design, fabrication and application of organic power converters: Driving light-emitting electrochemical cells from the $A C$ mains
}

Christian Larsen, Robert Forchheimer, Ludvig Edman and Deyu Tu

The self-archived version of this journal article is available at Linköping University Electronic Press:

http:/ / urn.kb.se/ resolve?urn=urn:nbn:se:liu:diva-138233

N.B.: When citing this work, cite the original publication.

Larsen, C., Forchheimer, R., Edman, L., Tu, D., (2017), Design, fabrication and application of organic power converters: Driving light-emitting electrochemical cells from the AC mains, Organic electronics, 45, 57-64. https:// dx.doi.org/ 10.1016/j.orgel.2017.02.036

Original publication available at:

https:/ / dx.doi.org/ 10.1016/j.orgel.2017.02.036

Copyright: Elsevier

http:// www.elsevier.com/

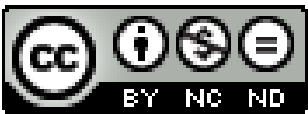




\title{
Design, Fabrication and Application of Organic Power Converters: Driving Light-emitting Electrochemical Cells from the AC Mains
}

\author{
Christian Larsen, Robert Forchheimer, Ludvig Edman ${ }^{*}$ and Deyu Tu*
}

\author{
Dr. C. Larsen and Prof. L. Edman
}

Department of Physics, Umeå University, SE-901 87 Umeå, Sweden

Prof. R. Forchheimer and Dr. D. Tu

Department of Electrical Engineering, Linköping University, SE-581 83 Linköping, Sweden

E-mail: L.E. (ludvig.edman@umu.se) and D.T. (deyu@isy.liu.se)

\begin{abstract}
The design, fabrication and operation of a range of functional power converter circuits, based on diode-configured organic field-effect transistors as the rectifying unit and capable of transforming a high AC input voltage to a selectable DC voltage, are presented. The converter functionality is demonstrated by selecting and tuning its constituents so that it can effectively drive a low-voltage organic electronic device, a light-emitting electrochemical cell (LEC), when connected to high-voltage AC mains. It is established that the preferred converter circuit for this task comprises an organic full-wave rectifier and a regulation resistor but is void of a smoothing capacitor, and that such a circuit connected to the AC mains $(230 \mathrm{~V}, 50 \mathrm{~Hz})$ successfully can drive an LEC to bright luminance $\left(360 \mathrm{~cd} \mathrm{~m}^{-2}\right)$ and high efficiency $\left(6.4 \mathrm{~cd} \mathrm{~A}^{-1}\right)$.
\end{abstract}

Keywords: organic power converters, diode-configured organic field-effect transistors, lightemitting electrochemical cells, solution processing, organic rectifiers 


\section{Introduction}

Printable organic electronic and photonic devices are beginning to reach a performance where a wide range of commercial applications are viable.[1-4] The complete development and integration of such devices into useful applications requires a compatible power supply to contribute the driving energy. Portable applications are envisioned to be powered by solar cells,[5-10] batteries,[11, 12] or even by wireless inductive transfer,[13] whereas fixed applications, such as general lighting,[14-19] signage[18, 20, 21] and electrochromic windows, $[10,22,23]$ would instead benefit of being connected to the AC mains power via a low-cost, light-weight, thin and environmental-friendly power converter. This converter should in addition preferably be printed or coated onto the same substrate as the device it is going to power, using similar solution-based processes in order to keep the cost of production at a minimum.

Power converters that are driven from the $A C$ mains depend on a constituent rectifier that can handle the high input voltage $\left(V_{\mathrm{AC}}=115\right.$ or $\left.230 \mathrm{~V}\right)$ while delivering a high current and high rectification during long-term operation. Organic Schottky diodes use a metal/organicsemiconductor junction for the rectification, and have demonstrated functional highfrequency operation and found application in, e.g., radio-frequency identification (RFID) tags.[24-26] Organic Schottky diodes can, however, not commonly tolerate the high input voltage provided by the AC mains, [27] and, to the best of our knowledge, no organic diode that can handle $>60 \mathrm{~V}$ has been reported. The unfortunate fact is that the stable handling of a high input voltage is very challenging for solution-processed organic-semiconductor films in general, and comparatively little attention has been geared towards solving this issue for the development of functional and low-cost organic power converters.[28-32]

In order to address this need, we have designed and fabricated a set of power converters based on solution-processed high-voltage organic field-effect transistors (OFETs), which are capable of converting an $\mathrm{AC}$ mains input of $V_{\mathrm{AC}}=230 \mathrm{~V}, f=50 \mathrm{~Hz}$, into a selectable rectified output voltage. As a design and application example, we present the successful driving of an organic light-emitting electrochemical cell (LEC) device to high luminance and efficiency by the small-footprint power converter. We also present a systematic study on how the power converter should be designed for different tasks and identify a low-complexity option fit for the connection to the $V_{A C}=115 \mathrm{VAC}$ mains and a higher-complexity option adopted for high-performance operation from the $V_{A C}=230 \mathrm{VAC}$ mains.

\section{Material and methods}

\subsection{The organic field-effect transistor}

The glass substrates (Eagle XG, Thin Film Devices) were cleaned by ultra-sonication for 10 min in isopropanol, blown dry with compressed air and dried in an oven at $120{ }^{\circ} \mathrm{C}$. 
Interdigitated source and drain electrodes comprising $25 \mathrm{~nm} \mathrm{Cr}$ and $25 \mathrm{~nm} \mathrm{Au}$, were patterned $\left(L_{G}=50 \mu \mathrm{m}\right.$ and $W_{D}=55.1 \mathrm{~mm}$ ) with a UV-lithographic lift-off process. After patterning the substrates were cleaned by ultra-sonication in isopropanol for $10 \mathrm{~min}$, blown dry with compressed air, and dried in an oven at $120^{\circ} \mathrm{C}$. Poly(3-hexylthiophene-2,5-diyl) (P3HT, regio-regular $M_{\mathrm{n}}=54,000-75,000 \mathrm{~g} \mathrm{~mol}^{-1}$, Sigma-Aldrich) was dissolved in chlorobenzene (anhydrous, Sigma-Aldrich) at a concentration of $10 \mathrm{mg} \mathrm{ml}^{-1}$ and stirred on a hotplate at $50{ }^{\circ} \mathrm{C}$ for $16 \mathrm{~h}$. Poly(methyl methacrylate) (PMMA, $M_{w}=996,000$, Sigma-Aldrich) was dissolved in butyl acetate (anhydrous, Sigma-Aldrich) at a concentration of $70 \mathrm{mg} \mathrm{ml}^{-1}$ and stirred on a hotplate at $70{ }^{\circ} \mathrm{C}$ for $16 \mathrm{~h}$. A P3HT film was spincoated onto the prepatterned OFET substrates at $2000 \mathrm{rpm}$ for $60 \mathrm{~s}$, and thereafter annealed at $120{ }^{\circ} \mathrm{C}$ for 15 min on a hotplate. The PMMA was spincoated on top of the P3HT film at $600 \mathrm{rpm}$ for $60 \mathrm{~s}$, and thereafter at $4000 \mathrm{rpm}$ for $20 \mathrm{~s}$. The spincoated films were dried on a hotplate at $70^{\circ} \mathrm{C}$ for $16 \mathrm{~h}$. The thickness of the P3HT and PMMA films were 35 and $2500 \mathrm{~nm}$, respectively, as measured using a stylus profilometer (DektakXT, Bruker). A $100 \mathrm{~nm}$ thick Al gate electrode was thermally evaporated onto the PMMA film through a shadow mask. The OFET devices were encapsulated with a cover glass by UV-curing an epoxy (E131, Ossila) by $10 \mathrm{~min}$ exposure in a UV-box. The OFET-based devices were characterized with a Keithley 4200-SCS measurement system. The $\mu_{\mathrm{h}}$ and $V_{\mathrm{T}}$ were extracted from the 3-terminal transfer data in the saturation regime by fitting equation (1) and using $\varepsilon_{\mathrm{r}}=3.8$ for PMMA:

$$
\sqrt{\mathrm{I}_{\mathrm{DS}}}=\sqrt{\frac{\mu_{\mathrm{h}} \mathrm{C}_{\mathrm{G}} \mathrm{W}_{\mathrm{D}}}{2 \mathrm{~L}_{\mathrm{G}}}}\left(\mathrm{V}_{\mathrm{GS}}-\mathrm{V}_{\mathrm{T}}\right)
$$

\subsection{The light-emitting electrochemical cell}

Indium tin oxide (ITO) coated glass substrates (20 $\Omega \mathrm{sq}^{-1}$, Thin Film Devices) were cleaned by ultra-sonication for $10 \mathrm{~min}$ in detergent, DI-water, acetone and isopropanol. Superyellow (SY, trade name: PDY-132, Merck) was dissolved in cyclohexanone (Sigma-Aldrich) to a concentration of $10 \mathrm{mg} \mathrm{ml}^{-1}$ and stirred on a hotplate at $50{ }^{\circ} \mathrm{C}$ for $24 \mathrm{~h}$. Hydroxyl-capped trimethylolpropane ethoxylate (TMPE-OH, $\mathrm{Mn}_{\mathrm{n}} \sim 450$, Sigma-Aldrich) and $\mathrm{KCF}_{3} \mathrm{SO}_{3}$ (SigmaAldrich) were dissolved in cyclohexanone at a concentration of $10 \mathrm{mg} \mathrm{ml}^{-1}$. The LEC ink was blended in a SY:TMPE-OH: $\mathrm{KCF}_{3} \mathrm{SO}_{3}$ mass ratio of 1:0.1:0.03 followed by a further dilution by adding 44 vol\% cyclohexanone. The LEC ink was spin-coated onto the ITO-coated glass substrates at $2000 \mathrm{rpm}$ and the resulting film dried at $70{ }^{\circ} \mathrm{C}$ for $4 \mathrm{~h}$. The $100 \mathrm{~nm}$ thick Al cathode was deposited by thermal evaporation. The overlapping ITO anode and Al cathode defined a light-emitting area of $2 \times 2 \mathrm{~mm}^{2}$. The LECs were encapsulated with a cover glass by using a UV-curable epoxy (E131, Ossila) exposed for $10 \mathrm{~min}$ in a UV-box. The LEC and OFET device fabrication were executed under inert $\mathrm{N}_{2}$ atmosphere $\left(\left[\mathrm{O}_{2}\right]<5 \mathrm{ppm}\right.$ and $\left[\mathrm{H}_{2} \mathrm{O}\right]<1$ ppm).

\subsection{The converter}


The diode-configured (DC) DC-OFET was realized by short circuiting the drain and the gate electrodes to form a 2-terminal device. The input AC voltage was regulated by a variable transformer (Iskra) and each measurement was initiated by rapidly increasing the input voltage from $0 \mathrm{~V}$ to either $V_{\mathrm{AC}}=115 \mathrm{~V}$ or $V_{\mathrm{AC}}=230 \mathrm{~V}$ during a time period of $\approx 1 \mathrm{~s}$. The temporal LEC voltage during rectifier driving was measured with a Picoscope 2203 (Pico Technology) measuring at a sampling rate of $10 \mathrm{kS} \mathrm{s}^{-1}$, and the LEC current was extracted by measuring the temporal voltage over a $10 \Omega$ resistor, in series with the LEC, and by using Ohm's law. The luminance was measured with an eye-response photodiode (BPW21, Osram) connected to a Keithley 4200-SCS, with the NPLC integration time set to 10 . The photodiode response was calibrated with a Konica Minolta LS-110 luminance meter. The operation of the rectifier and the LEC was performed in ambient atmosphere.

\section{Results and discussion}

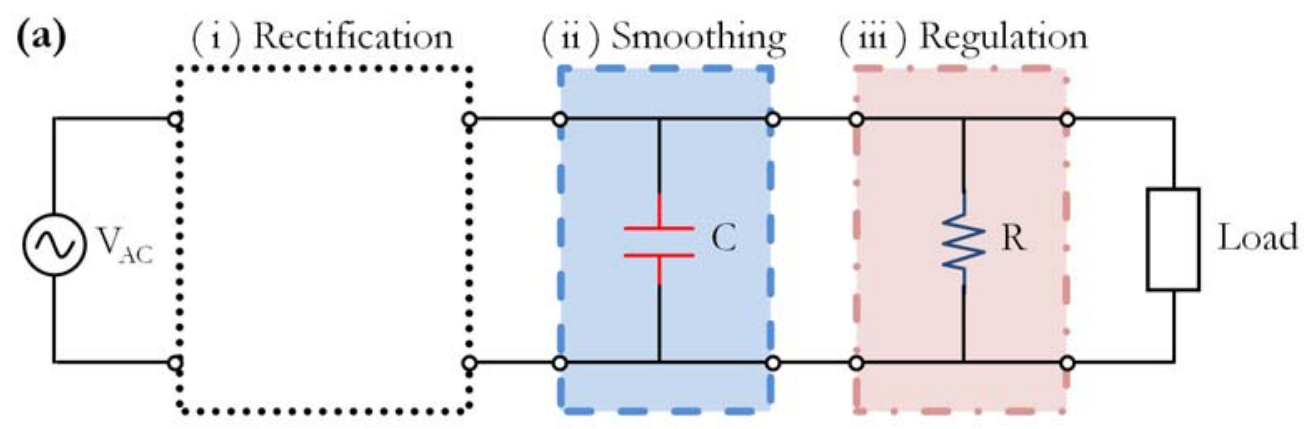

(b)
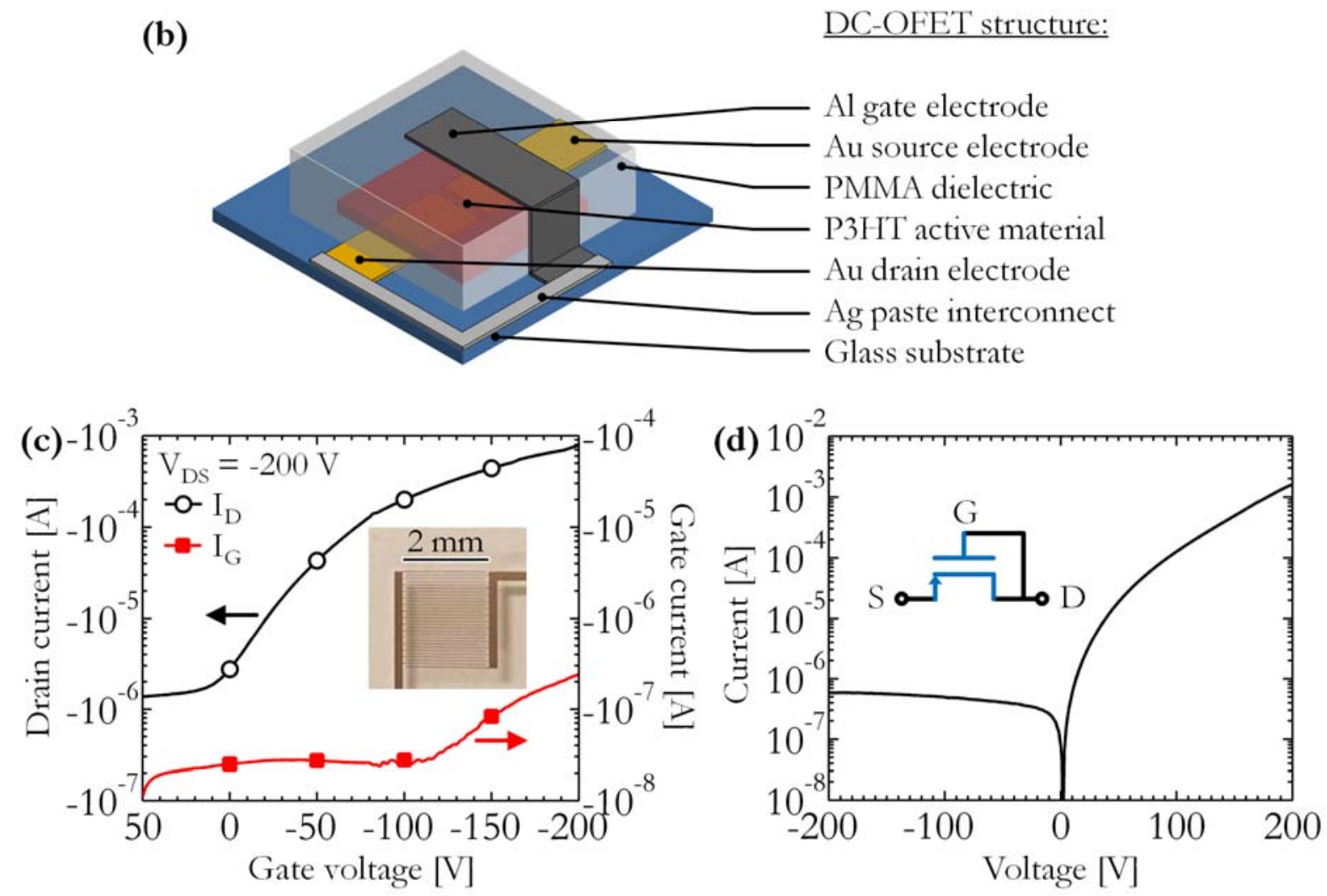
Figure 1. (a) The generic circuit diagram of the linear power converter, where the three boxes represent the sub-circuits for rectification, smoothing and regulation; and where the converter output is connected to a load. (b) A schematic of the DC-OFET device structure. (c) The transfer characteristics of a typical 3-terminal high-voltage OFET, measured at a drainsource voltage $=-200 \mathrm{~V}$. The inset shows a photograph of the interdigitated source/drain electrode structure. (d) The rectifying I-V characteristics for a typical two-terminal DC-OFET measured at a voltage ramp of $10 \mathrm{~V} \mathrm{~s}^{-1}$. The inset shows the DC-OFET circuit diagram.

The selected power converter constitutes a linear design, and its generic circuit diagram is presented in figure 1(a). It consists of three defined sub-circuit elements for (i) rectification, (ii) smoothing and (iii) regulation of the output voltage, which will be developed and discussed below. The converter output is herein utilized for the driving of a load in the form of a LEC device.

The task of rectification is commonly performed with a conventional two-terminal diode in order to force the current to pass in only the "forward" direction. However, in order to work off the $A C$ mains power, such a rectifying diode will need to be able to sustain the entire peak voltage ( $V_{\text {peak }}$ ) of the AC mains input without breaking down. For the $V_{\mathrm{AC}}=230 \mathrm{~V}$ mains, this corresponds to $V_{\text {peak }} \approx 325 \mathrm{~V}$. This high tolerance is difficult to achieve with an organic diode, as these devices typically only operate reliably in the $<20 \mathrm{~V}$ range without breaking down.[24, 26]

For this reason, we have instead made use of a three-terminal high-voltage OFET, with its gate and drain electrodes short circuited, for the task of current rectification. The inset in Figure 1 (d) presents the connection diagram of the two-terminal diode-configured DC-OFET, with the gate (G), drain (D) and source (S) electrodes identified. When appropriately contacted, it will only pass a current in the forward direction when the input voltage is larger than the transistor threshold voltage $\left(V_{T}\right)$ and feature a low sub-threshold current at reverse voltage. An important advantage with the DC-OFETs is that the breakdown voltage is determined by the properties of the insulating gate dielectric, specifically its dielectric strength and thickness, rather than the current-carrying active material.

We have fabricated and characterized top-gate, bottom-contact DC-OFETs with insulating poly(methyl methacrylate) (PMMA) as the dielectric and the semiconducting conjugated polymer poly(3-hexylthiophene-2,5-diyl) (P3HT) as the active material. A schematic of the device structure of the DC-OFET on a glass substrate is disclosed in figure $1(b)$. The source and drain Au electrodes were patterned into an interdigitated structure by photolithography for a large channel width $\left(W_{D}=55.1 \mathrm{~mm}\right)$ and for the sustainment of a high output current. A photograph of the interdigitated source/drain electrode structure is included as the inset in figure $1(\mathrm{c})$. The active material and the dielectric were sequentially spin coated from solution onto the source and drain electrodes from orthogonal solvents, before the top gate 
electrode was deposited by thermal evaporation. The device structure was capped off by an epoxy-attached cover-glass to allow for long-term operation under ambient air.[33, 34] The details of the fabrication procedure can be found in section 2.1 .

A typical transfer measurement on a 3-terminal high-voltage OFET is shown in figure 1 (c). The extracted hole mobility of the P3HT active material was $\mu_{\mathrm{h}}=2.6( \pm 0.1) \times 10^{-2} \mathrm{~cm}^{2} \mathrm{~V}^{-1} \mathrm{~s}^{-1}$ and the threshold voltage of the OFET was $V_{T}=1.7( \pm 2.3) \mathrm{V}$. These values are the average of 16 measurements on unique encapsulated OFET devices, and comparable to data for P3HTbased OFET devices in the literature.[33, 35]

Importantly, with the thickness of the PMMA dielectric being $2.5 \mu \mathrm{m}$, and with the gate and drain terminals shorted with a Ag paste interconnect (see Figure 1(b)), we could obtain a desired stable rectifying operation from the DC-OFET within an input voltage range of $\pm 325 \mathrm{~V}$, i.e. at $\pm V_{\text {peak }}$ for the $V_{\mathrm{AC}}=230 \mathrm{~V}$ mains. Figure $1(\mathrm{~d})$ shows the 2-terminal current-voltage $(I-V)$ trace of the DC-OFET. We call attention to the high current rectifying ratio of $3 \times 10^{3}$ at an input voltage of $\pm 200 \mathrm{~V}$, the high output current of $1.6 \mathrm{~mA}$, and the fact that the encapsulated DC-OFET could be turned on and off under ambient air for prolonged times without a noticeable drop in performance. We have also performed step-input measurements on the 3-terminal high-voltage OFET, and measured typical rise and falltimes of $0.7 \mathrm{~ms}$ and $0.1 \mathrm{~ms}$, respectively (figure S1). The necessary switching time of $<10 \mathrm{~ms}$ for a power converter driven by $50 \mathrm{~Hz} \mathrm{AC}$ mains should thus be attainable with the corresponding DC-OFET device. 
(a)

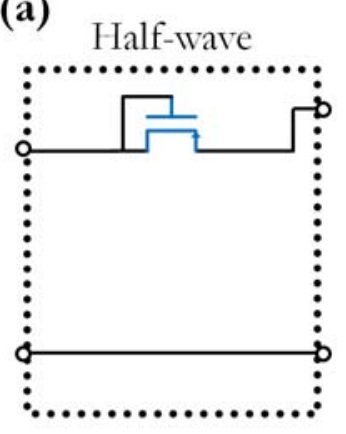

(b)

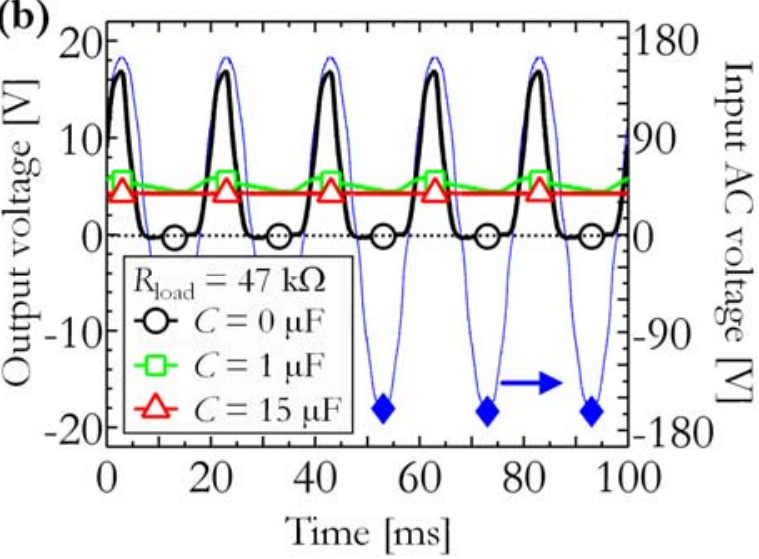

(c)

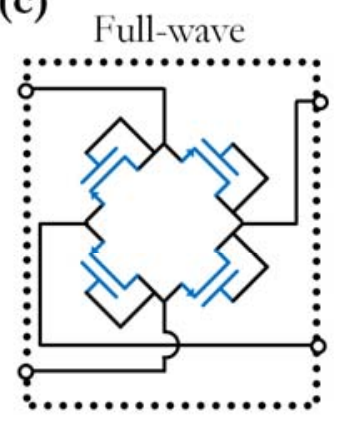

(d)

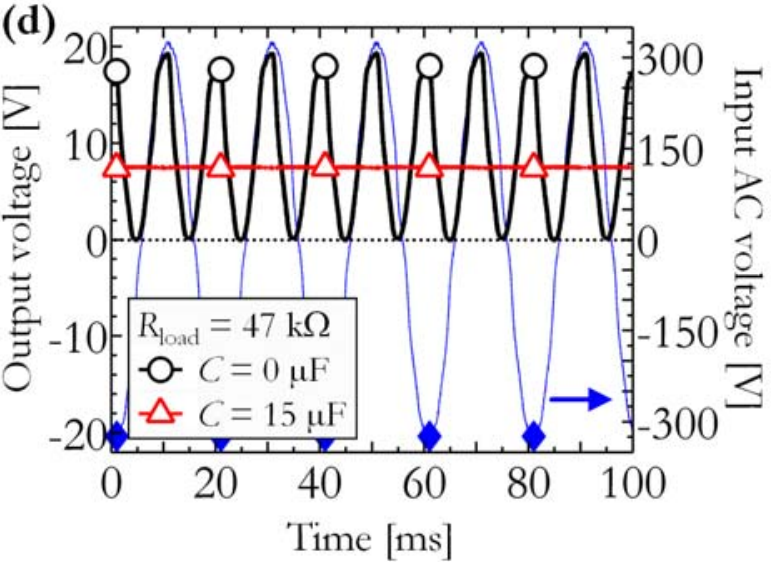

Figure 2. (a) The half-wave rectification circuit, and (c) the full-wave rectification circuit, comprising solely DC-OFETs. (b) The input voltage (solid blue diamonds) and output voltage (open symbols) as a function of time for the half-wave rectification circuits driven by a $V_{A C}=$ $115 \mathrm{~V}, 50 \mathrm{~Hz}$, input. (d) The temporal data for the full-wave rectification circuits driven by a $V_{A C}=230 \mathrm{~V}$ input. The output data, in (b) and (d), were measured over a $47 \mathrm{k} \Omega$ load resistor, and the different smoothing capacitors are identified in the insets. The dotted lines indicate 0 $\checkmark$ for clarity.

Figure 2(a) and 2(c) present the schematic diagrams for the half-wave rectifier and the fullwave rectifier sub-circuits, respectively. It is notable that the only circuit element is the DCOFET. Figure 2(b) displays the $V_{\mathrm{AC}}=115 \mathrm{~V}, f=50 \mathrm{~Hz}$, input voltage (solid blue diamonds) and the corresponding output voltage, measured over a $47 \mathrm{k} \Omega$ load resistor, from half-wave rectifier sub-circuits connected in parallel to a smoothing sub-circuit (see figure $1(a)$ ). The three circuits were distinguished by the selection of the smoothing capacitor: $C=0 \mu \mathrm{F}, C=1$ $\mu \mathrm{F}$, and $C=15 \mu \mathrm{F}$.

With no smoothing capacitor (open black circles), the output voltage features half-wave pulses with a frequency of $f=50 \mathrm{~Hz}, V_{\text {peak }}=16.8 \mathrm{~V}$ and $V_{\min }=-0.3 \mathrm{~V}$. By including a small smoothing capacitor ( $C=1 \mu \mathrm{F}$; open green squares), the output voltage features a ripple shape with a small amplitude of $V_{\text {ripple }} \approx 1.4 \mathrm{~V}$ centered around an average voltage of $5 \mathrm{~V}$. 
The ripple magnitude is determined by the load current ( $/$ load $)$, the switching frequency $(f)$ and the size of the smoothing capacitor and can be estimated through $V_{\text {ripple }}=I_{\text {load }} /(f \times C)$. With a large smoothing capacitor ( $C=15 \mu \mathrm{F}$; open red triangles), the output from the halfwave-rectification/smoothing circuit is essentially constant, and it delivers a DC voltage of $4.2 \mathrm{~V}$ and a DC current of $90 \mu \mathrm{A}$ over the constant-resistance load.

Figure 2 (d) shows the result when a $V_{\mathrm{AC}}=230 \mathrm{~V}, f=50 \mathrm{~Hz}$, input voltage (solid blue diamonds) drives a full-wave rectifier circuit as is (open black circles) or when connected to a smoothing circuit comprising a $C=15 \mu \mathrm{F}$ capacitor (open red triangles). The circuit void of the smoothing capacitor produces a doubling of the input frequency to $100 \mathrm{~Hz}, V_{\text {peak }}=19.4 \mathrm{~V}$ and $V_{\text {min }}=0 \mathrm{~V}$; whereas the circuit including the large smoothing capacitor delivers a constant output voltage and current of $7.5 \mathrm{~V}$ and $160 \mu \mathrm{A}$ over the load. These results thus demonstrate that the DC-OFET based power converter is capable of transforming a high AC input voltage into a more practical low DC output voltage, and that it can deliver a sizeable output current through a resistive load. It should however be noted that a significant portion of the input power is lost over the transistors. It is thus advisable that future work on the organic power converter should focus on improving the transistor performance, e.g. by employing a higher mobility organic semiconductor [36], or by enlarging the width of the transistor channel, or by a combination of both.

In this study we selected the load to be driven by the power converter to be a light-emitting electrochemical cell (LEC). It is a thin-film device positioned on a substrate, comprising a blend of a light-emitting organic semiconductor and an electrolyte (i.e. mobile ions) as the active material sandwiched between two charge-injecting electrodes. When a voltage is applied between the two LEC electrodes, the mobile ions in the active material redistribute to form electric double layers at the electrode interfaces, which facilitate for efficient charge injection and electrochemical doping of the organic semiconductor.[37] Electrochemical ptype doping takes place at the positive anode and n-type doping the negative cathode, and after a "turn-on time" a light-emitting $p$-n junction has formed in the bulk of the active material.[38-40] The demonstrated advantages of the LEC, as facilitated by its operation, are that it can comprise of air-stable electrodes, a thick single-layer active material, and that it as a consequence can be fabricated with high-throughput and low-cost solution-based methods.[15, 16, 19, 41-43]

The herein employed LECs comprise an active-material blend of the organic semiconducting polymer Superyellow and an TMPE-OH: $\mathrm{KCF}_{3} \mathrm{SO}_{3}$ electrolyte sandwiched between an $\mathrm{Al}$ cathode and an indium tin oxide (ITO) anode; details of the device fabrication are available in section 2.2. Figure S2 presents the current-time response of an Al/(Superyellow:TMPE$\mathrm{OH}: \mathrm{KCF}_{3} \mathrm{SO}_{3}$ )/ITO LEC, with an active light-emission area of $2 \times 2 \mathrm{~mm}^{2}$, and driven by a constant voltage of $V_{D C}=4 \mathrm{~V}$. It reveals that the current increases from $10 \mathrm{nA}$ to $60 \mu \mathrm{A}$ during the turn-on process, which corresponds to a decrease of the effective device resistance by four orders of magnitude from $400 \mathrm{M} \Omega$ to $67 \mathrm{k} \Omega$. 
For converter circuits comprising a linear combination of the rectifier and the smoothing sub-circuits, this significant temporal change of the resistance of the LEC load can represent a challenge. More specifically, if the initial high resistance of the LEC is similar to, or larger than, the effective resistance of the rectifier circuit, this will result in that the LEC load is exposed to a detrimental high voltage during turn-on through voltage division between the rectifier sub-circuit and the LEC load. Thus, in order to limit the voltage over the LEC load during the turn-on process, a "regulation sub-circuit" comprising a regulation resistor was connected in parallel to the LEC load (see figure 1(a)), with the aim of decreasing the effective load resistance during startup. The resistance of the regulation resistor was chosen so that it is markedly smaller than the LEC at $t=0$, but significantly larger than the LEC during steady-state light emission. The output voltage will then be limited by the regulation resistor during the initial operation and by the LEC load during the subsequent steady-state operation. An analysis of the LEC operational data suggested that a $470 \mathrm{k} \Omega$ regulation resistor could be appropriate for our specific devices. This regulation resistor was included into the converter circuit in all of the subsequent measurements. 

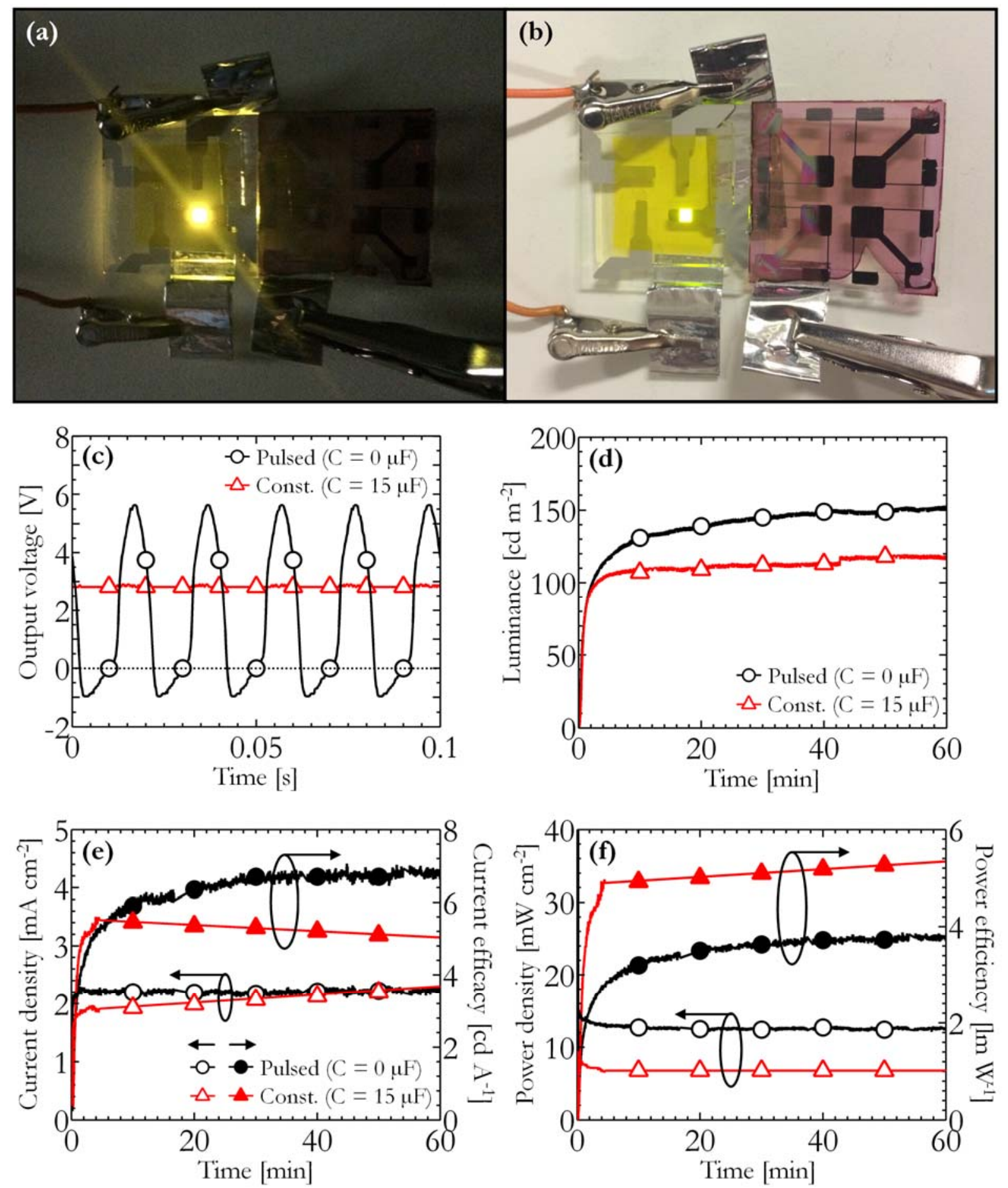

Figure 3. Photographs of a yellow-emitting LEC device driven by the pulsed output from a half-wave converter during operation (a) in darkness and (b) under ambient light. The converter comprised a thin-film DC-OFET rectifier (purple device to the right), a regulation resistor connected via the wires to the left, and it was connected to a $V_{A C}=115 \mathrm{~V}, f=50 \mathrm{~Hz}$ input. (c) The temporal output voltage of the half-wave rectifier at $V_{A C}=115 \mathrm{~V}, f=50 \mathrm{~Hz}$ input, as measured over the LEC load at steady-state. The black circles represents pulsed output $(C=O \mu F)$ and the red triangles represents the constant output $(C=15 \mu \mathrm{F})$. The dotted 
line indicates $0 \vee$ for clarity. (d-f) The first 1-hour of LEC operation during pulsed driving (circles) and constant driving (triangles), as provided by the half-wave converter.

Table 1. LEC performance metrics at steady-state, as extracted from devices under pulsed and constant driving. The half-wave converter was connected to the $V_{\mathrm{AC}}=115 \mathrm{~V}, f=50 \mathrm{~Hz}$ mains and the full-wave converter to the $V_{A C}=230 \mathrm{~V}, f=50 \mathrm{~Hz}$ mains.

\begin{tabular}{c|cccccc}
\multicolumn{2}{c}{$\begin{array}{c}\text { Converter } \\
\text { configuration }\end{array}$} & $\begin{array}{c}\text { Peak } \\
\text { Luminance } \\
{\left[\mathrm{cd} \mathrm{m}^{-2}\right]}\end{array}$ & $\begin{array}{c}\text { Current } \\
\text { Density } \\
{\left[\mathrm{mA} \mathrm{cm}^{-2}\right]}\end{array}$ & $\begin{array}{c}\text { Current } \\
\text { Efficacy } \\
{\left[\mathrm{cd} \mathrm{A}^{-1}\right]}\end{array}$ & $\begin{array}{c}\text { Power } \\
\text { Density } \\
{\left[\mathrm{mW} \mathrm{cm}^{-2}\right]}\end{array}$ & $\begin{array}{c}\text { Power } \\
\text { Efficiency } \\
{\left[\mathrm{Im} \mathrm{W}^{-1}\right]}\end{array}$ \\
\hline \hline \multirow{2}{*}{$\begin{array}{c}\text { Half-wave } \\
\mathbf{1 1 5} \mathbf{V}\end{array}$} & Pulsed & 150 & 2.2 & 6.7 & 12.6 & 3.8 \\
\cline { 2 - 7 } & Constant & 110 & 2.3 & 5.0 & 6.5 & 5.5 \\
\hline \multirow{2}{*}{$\begin{array}{c}\text { Full-wave } \\
\mathbf{2 3 0} \mathbf{~ V}\end{array}$} & Pulsed & 360 & 5.7 & 6.4 & 22 & 5.3 \\
\cline { 2 - 7 } & Constant & 320 & 5.9 & 5.4 & 20 & 5.1 \\
\hline
\end{tabular}

With the goal of identifying a functional converter design for the efficient driving of LEC devices, a range of different converter circuits based on the half-wave and the full-wave rectifier were investigated. We begin with the half-wave converter that in turn was connected to the $V_{\mathrm{AC}}=115 \mathrm{~V}, f=50 \mathrm{~Hz}$, input $\mathrm{AC}$ mains. Figure $3(\mathrm{a})$ and $3(\mathrm{~b})$ present two photographs of a yellow-emitting LEC device driven by a half-wave converter while operating in darkness and under ambient light, respectively. The DC-OFET can be identified as the thinfilm purple device positioned to the right in the photographs, while the regulation resistor is connected via the clamps to the left.

The temporal behavior of the output voltage over the LEC load at steady state, when driven by two different half-wave converter circuits, is shown in figure 3(c). The half-wave converter void of a smoothing capacitor $(C=0 \mu \mathrm{F})$ produces non-symmetric pulses (black circles) with a positive peak value of $+5.6 \mathrm{~V}$ and a negative peak value of $-1.0 \mathrm{~V}$. The negative component is the result of that a minor current is leaking through the DC-OFET in its offstate. The addition of a $15 \mu \mathrm{F}$ smoothing capacitor to the converter circuit produces a constant positive output voltage of $V_{D C}=2.8 \mathrm{~V}$ (red triangles). For simplicity, the former driving protocol is termed "pulsed" and the latter "constant".

The temporal response of the LEC device during driving by the two different half-wave converters is presented in figure $3(\mathrm{~d})$-(f), and key data are summarized in Table 1. (Note that the data in figure 3(d)-(f) and 4(b)-(d) are averaged over a period of $1 \mathrm{~s}$, so that the $50 \mathrm{~Hz}$ variation in the driving input is not distinguishable.) Figure $3(d)$ shows that pulsed driving (black circles) and constant driving (red triangles) result in approximately the same LEC turn- 
on time of 2-3 min to $100 \mathrm{~cd} \mathrm{~m}^{-2}$, but that a higher peak luminance of $150 \mathrm{~cd} \mathrm{~m}^{-2}$ is obtained during pulsed driving. As the current density is comparable for both operational modes (figure 3(e), open symbols), the pulsed driving also results in a higher peak current efficacy of $6.7 \mathrm{~cd} \mathrm{~A}^{-1}$ (figure 3(e), solid symbols). These findings are in line with previous studies on LEC devices based on ionic transition metal complexes as the light-emitting organic semiconductor, where a pulsed operational protocol, albeit at a much higher frequency, has been reported to result in a high performance.[44-46] It is plausible that pulsed bias in contrast to constant bias will prohibit the full growth and extension of the doping regions, and that undesired doping-induced exciton quenching reaction as a consequence can be suppressed.[44-49]

However, figure 3(f) shows that the consumed power density (i.e. the product of the current density and the voltage) is notably higher during pulsed driving, which results in that the peak power conversion efficacy is actually better for the LEC driven by the constant bias. We also find that the stability of LECs driven by the pulsed bias from the half-wave converter is rather limited, presumably since the negative voltage transients will produce electrochemical side reactions at the reverse biased electrodes.[50-52]

The AC mains in most of Europe, Africa, Asia, Australia, and South America operate at $V_{A C}=$ $230 \mathrm{~V}$ and not at $V_{A C}=115 \mathrm{~V}$, but we find that the stability of the half-wave rectifier converter circuit itself is limited during long-term operation at $V_{\mathrm{AC}}=230 \mathrm{~V}$ (see figure $\mathrm{S} 3(\mathrm{a})$ ) (c)); presumably since a single DC-OFET device has to carry the entire power load during operation (see figure $1(\mathrm{a})$ and $2(\mathrm{a})$ ), which can lead to severe self-heating in its active material. With that in mind, we shift our attention to the full-wave converter, as it splits the dissipated power during operation between two serially connected DC-OFETs (see figure 1(a) and $2(c))$ and self-heating as a consequence should be less of an issue. 

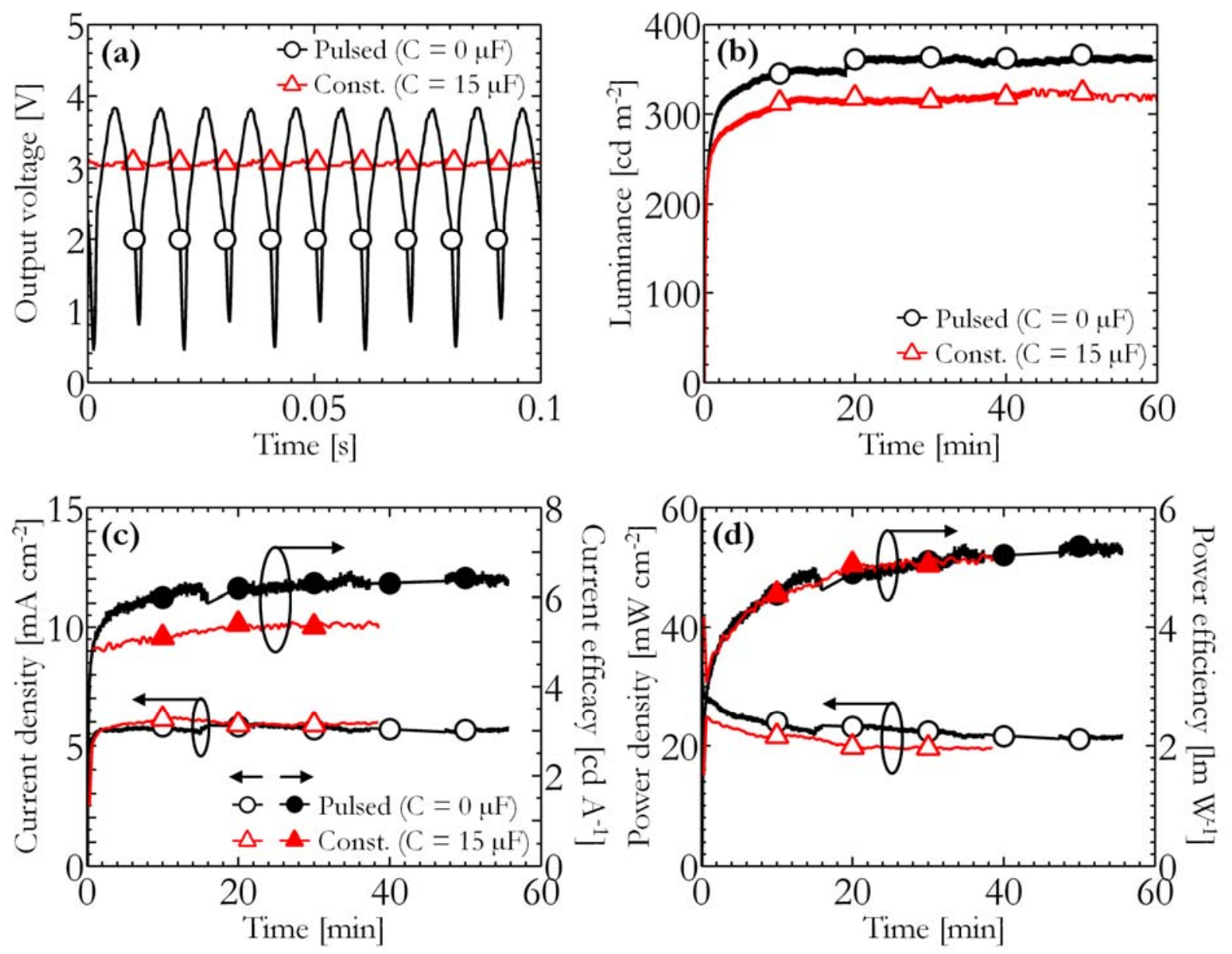

Figure 4. (a) The temporal output voltage of the full-wave rectifier at $V_{A C}=230 \mathrm{~V}, f=50 \mathrm{~Hz}$ input, as measured over the LEC load at steady-state. The black circles represent the pulsed $(C=0 \mu F)$ and the red triangles represents the constant $(C=15 \mu F)$ output voltage. $(b-d)$ The first 1-hour of LEC operation during pulsed driving (circles) and constant driving (triangles), as provided by the full-wave converter.

Figure 4(a) presents the temporal output voltage over the LEC load at steady-state operation, when driven by full-wave converters connected to a $V_{\mathrm{AC}}=230 \mathrm{~V}, f=50 \mathrm{~Hz}$, input. For the fullwave converter void of a smoothing capacitor $(C=0 \mu \mathrm{F})$, the load voltage features pulses between $0.5 \mathrm{~V}$ and $3.8 \mathrm{~V}$ appearing at a frequency of $100 \mathrm{~Hz}$ (black circles); whereas the converter including a $15 \mu \mathrm{F}$ smoothing capacitor produces an almost constant voltage of 3.1 $\checkmark$ (red triangles). Again, we term these two driving modes as "pulsed" and "constant" for simplicity.

The temporal response of the LEC devices during driving by the two different full-wave converters is presented in figure $4(\mathrm{~b})-(\mathrm{d})$, and key data are summarized in Table 1 . We find that the pristine LECs turn on fast and reach a luminance of $>100 \mathrm{~cd} \mathrm{~m}^{-2}$ within $8 \mathrm{~s}$, during both pulsed and constant output voltages as provided by the full-wave converter. Overall, the LECs driven by the pulsed output from the full-wave converter performs slightly better 
than LECs driven by the constant output, as quantified by a higher peak luminance of $360 \mathrm{~cd}$ $\mathrm{m}^{-2}$, a current efficacy of $6.4 \mathrm{~cd} \mathrm{~A}^{-1}$ and a power conversion efficacy at peak luminance of 5.3 Im $\mathrm{W}^{-1}$. We observe no signs of LEC degradation during the 1-hour measurement cycle, which is in sharp contrast to the case for the LEC devices driven by the pulsed bias provided by the half-wave converter connected to the same $A C$ mains voltage of $V_{A C}=230 \mathrm{~V}, f=50 \mathrm{~Hz}$ (see figure S3). We attribute the improved LEC stability to the removal of negative voltage spikes during the full-wave converter operation. We further note that the LEC devices driven by the full-wave converter in general features an efficiency on par or better than the corresponding devices driven by the half-wave converter, despite being driven at a much higher luminance (see Table 1). Finally, we find that the stress stability of the driving circuitry is significantly improved by the utilization of the full-wave converter design over its halfwave equivalent, as deduced from the transistor stability study presented in figure S3(d).

Based on our above findings, we propose that two particularly viable options exist for the design of an organic-based converter circuit fit for the driving of LEC devices from the AC mains. First, for the connection to $A C$ mains with the lower $V_{A C}=115 \mathrm{~V}$ rating, the constant output voltage from a half-wave converter circuit comprising a single DC-OFET connected in parallel with a smoothing capacitor and a protection resistor is attractive due to its lower complexity. Second, for the connection to $\mathrm{AC}$ mains with the higher $V_{\mathrm{AC}}=230 \mathrm{~V}$ rating or for the attainment of a maximum LEC performance, it is instead preferable to employ a fullwave converter circuit comprising four DC-OFETs connected in parallel with a protection resistor.

Finally, in the context of LEC driving, we only find one preceding piece of work. Malliaras and co-workers introduced a notably non-complex approach, when they allowed a large number of "cascaded" LECs to be connected directly to the $V_{A C}=120 \mathrm{~V}, f=60 \mathrm{~Hz}, \mathrm{AC}$ mains through voltage division. $[53,54]$ While this approach is straightforward, it puts tough restrictions on the appropriate LEC device and circuit design in order to make it compatible with the nonvariable input. The employment of a converter circuit is more general and adaptable as its voltage output can be tuned for the specific input requirements of each specific LEC device and circuit.

\section{Conclusion}

A range of different organic-based power converters, based on diode-connected organic transistors in a half-wave or a full-wave configuration, have been designed, tested and evaluated for the driving of light-emitting electrochemical cells. With the input from the high-voltage $A C$ mains $\left(V_{\mathrm{AC}}=230 \mathrm{~V}, f=50 \mathrm{~Hz}\right)$, the full-wave converter including a regulating resistor but void of a smoothing capacitor is shown to be capable of driving an LEC device to fast turn on, bright luminance and high efficiency. The demonstration of a functional integrated converter and light-emitting device circuit that is light-weight, thin and potentially 
low-cost, and which can be driven directly from a normal electrical outlet, promises to be of relevance in a variety of future fixed emissive applications.

\section{Acknowledgements}

The authors acknowledge financial support from the Swedish Foundation for Strategic Research, the Swedish Research Council, the Swedish Energy Agency, Kempestiftelserna and the Knut and Alice Wallenberg Foundation.

\section{Supporting Information}

Supporting Information relating to this article is appended.

\section{References}

1. R.S. Deol, H.W. Choi, M. Singh, and G.E. Jabbour, Printable Displays and Light Sources for Sensor Applications: A Review. IEEE Sensors Journal, 2015. 15(6): p. 3186-3195.

2. $\quad$ K.T. Kamtekar, A.P. Monkman, and M.R. Bryce, Recent Advances in White Organic Light-Emitting Materials and Devices (WOLEDs). Advanced Materials, 2010. 22(5): p. 572-582.

3. C.D. Muller, A. Falcou, N. Reckefuss, M. Rojahn, V. Wiederhirn, P. Rudati, H. Frohne, O. Nuyken, H. Becker, and K. Meerholz, Multi-colour organic light-emitting displays by solution processing. Nature, 2003. 421(6925): p. 829-833.

4. A. Nathan, A. Ahnood, M.T. Cole, S. Lee, Y. Suzuki, P. Hiralal, F. Bonaccorso, T. Hasan, L. Garcia-Gancedo, A. Dyadyusha, S. Haque, P. Andrew, S. Hofmann, J. Moultrie, D. Chu, A.J. Flewitt, A.C. Ferrari, M.J. Kelly, J. Robertson, G.A.J. Amaratunga, and W.I. Milne, Flexible Electronics: The Next Ubiquitous Platform. Proceedings of the IEEE, 2012. 100(Special Centennial Issue): p. 1486-1517.

5. A. Mei, X. Li, L. Liu, Z. Ku, T. Liu, Y. Rong, M. Xu, M. Hu, J. Chen, Y. Yang, M. Grätzel, and H. Han, A hole-conductor-free, fully printable mesoscopic perovskite solar cell with high stability. Science, 2014. 345(6194): p. 295-298.

6. P. Kopola, T. Aernouts, R. Sliz, S. Guillerez, M. Ylikunnari, D. Cheyns, M. Välimäki, M. Tuomikoski, J. Hast, G. Jabbour, R. Myllylä, and A. Maaninen, Gravure printed flexible organic photovoltaic modules. Solar Energy Materials and Solar Cells, 2011. 95(5): p. 1344-1347.

7. F.C. Krebs, Fabrication and processing of polymer solar cells: A review of printing and coating techniques. Solar Energy Materials and Solar Cells, 2009. 93(4): p. 394412.

8. N.-G. Park, M. Grätzel, T. Miyasaka, K. Zhu, and K. Emery, Towards stable and commercially available perovskite solar cells. Nature Energy, 2016. 1: p. 16152. 
9. A. Hagfeldt, G. Boschloo, L. Sun, L. Kloo, and H. Pettersson, Dye-Sensitized Solar Cells. Chemical Reviews, 2010. 110(11): p. 6595-6663.

10. J. Jensen, H.F. Dam, J.R. Reynolds, A.L. Dyer, and F.C. Krebs, Manufacture and demonstration of organic photovoltaic-powered electrochromic displays using roll coating methods and printable electrolytes. Journal of Polymer Science Part B: Polymer Physics, 2012. 50(8): p. 536-545.

11. L. Nyholm, G. Nyström, A. Mihranyan, and M. Strømme, Toward Flexible Polymer and Paper-Based Energy Storage Devices. Advanced Materials, 2011. 23(33): p. 3751-3769.

12. H. Nishide and K. Oyaizu, Toward Flexible Batteries. Science, 2008. 319(5864): p. 737-738.

13. G.A. Covic and J.T. Boys, Inductive Power Transfer. Proceedings of the IEEE, 2013. 101(6): p. 1276-1289.

14. C. Zhong, C. Duan, F. Huang, H. Wu, and Y. Cao, Materials and Devices toward Fully Solution Processable Organic Light-Emitting Diodes. Chemistry of Materials, 2011. 23(3): p. 326-340.

15. A. Sandstrom, A. Asadpoordarvish, J. Enevold, and L. Edman, Spraying Light: Ambient-Air Fabrication of Large-Area Emissive Devices on Complex-Shaped Surfaces. Adv Mater, 2014.

16. A. Sandstrom, H.F. Dam, F.C. Krebs, and L. Edman, Ambient fabrication of flexible and large-area organic light-emitting devices using slot-die coating. Nat Commun, 2012. 3: p. 1002.

17. M.A. Baldo, D.F. O'Brien, Y. You, A. Shoustikov, S. Sibley, M.E. Thompson, and S.R. Forrest, Highly efficient phosphorescent emission from organic electroluminescent devices. Nature, 1998. 395(6698): p. 151-154.

18. D. Tordera, S. Meier, M. Lenes, R.D. Costa, E. Ortí, W. Sarfert, and H.J. Bolink, Simple, Fast, Bright, and Stable Light Sources. Advanced Materials, 2012. 24(7): p. 897-900.

19. A. Sandström and L. Edman, Towards High-Throughput Coating and Printing of Light-Emitting Electrochemical Cells: A Review and Cost Analysis of Current and Future Methods. Energy Technology, 2015. 3(4): p. 329-339.

20. E.M. Lindh, A. Sandström, M. Andersson, and L. Edman, Luminescent Line Art by Direct-Write Patterning. Light: Science \& Applications, 2016. 5: p. Accepted article preview.

21. E.M. Lindh, A. Sandström, and L. Edman, Inkjet Printed Bilayer Light-Emitting Electrochemical Cells for Display and Lighting Applications. Small, 2014. 10(20): p. 4148-4153.

22. P. Andersson, R. Forchheimer, P. Tehrani, and M. Berggren, Printable All-Organic Electrochromic Active-Matrix Displays. Advanced Functional Materials, 2007. 17(16): p. 3074-3082.

23. G.A. Niklasson and C.G. Granqvist, Electrochromics for smart windows: thin films of tungsten oxide and nickel oxide, and devices based on these. Journal of Materials Chemistry, 2007. 17(2): p. 127-156.

24. S. Steudel, K. Myny, V. Arkhipov, C. Deibel, S. De Vusser, J. Genoe, and P. Heremans, $50 \mathrm{MHz}$ rectifier based on an organic diode. Nat Mater, 2005. 4(8): p. 597600.

25. C.-Y. Lin, C.-H. Tsai, H.-T. Lin, L.-C. Chang, Y.-H. Yeh, Z. Pei, Y.-R. Peng, and C.$\mathrm{C}$. $\mathrm{Wu}$, High-frequency polymer diode rectifiers for flexible wireless powertransmission sheets. Organic Electronics, 2011. 12(11): p. 1777-1782. 
26. P.S. Heljo, M. Li, K.E. Lilja, H.S. Majumdar, and D. Lupo, Printed Half-Wave and Full-Wave Rectifier Circuits Based on Organic Diodes. IEEE Transactions on Electron Devices, 2013. 60(2): p. 870-874.

27. S. Steudel, S. De Vusser, K. Myny, M. Lenes, J. Genoe, and P. Heremans, Comparison of organic diode structures regarding high-frequency rectification behavior in radio-frequency identification tags. Journal of Applied Physics, 2006. 99(11): p. 114519.

28. M.A. Smith, R.P. Gowers, A. Shih, and A.I. Akinwande, High-Voltage Organic ThinFilm Transistors on Flexible and Curved Surfaces. IEEE Transactions on Electron Devices, 2015. 62(12): p. 4213-4219.

29. V. Keshmiri, C. Larsen, L. Edman, R. Forchheimer, and D. Tu, A Current Supply with Single Organic Thin-Film Transistor for Charging Supercapacitors. ECS Transactions, 2016. 75(10): p. 217-222.

30. V. Fiore, P. Battiato, S. Abdinia, S. Jacobs, I. Chartier, R. Coppard, G. Klink, E. Cantatore, E. Ragonese, and G. Palmisano, An Integrated 13.56-MHz RFID Tag in a Printed Organic Complementary TFT Technology on Flexible Substrate. IEEE Transactions on Circuits and Systems I: Regular Papers, 2015. 62(6): p. 1668-1677.

31. M. Uno, B.-S. Cha, Y. Kanaoka, and J. Takeya, High-speed organic transistors with three-dimensional organic channels and organic rectifiers based on them operating above $20 \mathrm{MHz}$. Organic Electronics, 2015. 20: p. 119-124.

32. M. Uno, Y. Kanaoka, B.-S. Cha, N. Isahaya, M. Sakai, H. Matsui, C. Mitsui, T. Okamoto, J. Takeya, T. Kato, M. Katayama, Y. Usami, and T. Yamakami, ShortChannel Solution-Processed Organic Semiconductor Transistors and their Application in High-Speed Organic Complementary Circuits and Organic Rectifiers. Advanced Electronic Materials, 2015. 1(12): p. 1500178-n/a.

33. Y. Fu and F.-Y. Tsai, Air-stable polymer organic thin-film transistors by solutionprocessed encapsulation. Organic Electronics, 2011. 12(1): p. 179-184.

34. A. Asadpoordarvish, A. Sandstrom, S. Tang, J. Granstrom, and L. Edman, Encapsulating light-emitting electrochemical cells for improved performance. Applied Physics Letters, 2012. 100(19).

35. A. Facchetti, M.H. Yoon, and T.J. Marks, Gate Dielectrics for Organic Field-Effect Transistors: New Opportunities for Organic Electronics. Advanced Materials, 2005. 17(14): p. 1705-1725.

36. M Gsänger, D. Bialas, L. Huang, M. Stolte, and F. Würthner, Organic Semiconductors based on Dyes and Color Pigments. Advanced Materials, 2016. 28(19): p. 3615-3645.

37. Q.B. Pei, G. Yu, C. Zhang, Y. Yang, and A.J. Heeger, POLYMER LIGHT-EMITTING ELECTROCHEMICAL-CELLS. Science, 1995. 269(5227): p. 1086-1088.

38. P. Matyba, K. Maturova, M. Kemerink, N.D. Robinson, and L. Edman, The dynamic organic p-n junction. Nature Materials, 2009. 8(8): p. 672-676.

39. S.B. Meier, S. van Reenen, B. Lefevre, D. Hartmann, H.J. Bolink, A. Winnacker, W. Sarfert, and M. Kemerink, Dynamic Doping in Planar Ionic Transition Metal Complex-Based Light-Emitting Electrochemical Cells. Advanced Functional Materials, 2013. 23(28): p. 3531-3538.

40. S. van Reenen, P. Matyba, A. Dzwilewski, R.A.J. Janssen, L. Edman, and M. Kemerink, A Unifying Model for the Operation of Light-Emitting Electrochemical Cells. Journal of the American Chemical Society, 2010. 132(39): p. 13776-13781.

41. A. Asadpoordarvish, A. Sandström, C. Larsen, R. Bollström, M. Toivakka, R. Österbacka, and L. Edman, Light-Emitting Paper. Advanced Functional Materials, 2015: p. n/a-n/a. 
42. G. Hernandez-Sosa, S. Tekoglu, S. Stolz, R. Eckstein, C. Teusch, J. Trapp, U.

Lemmer, M. Hamburger, and N. Mechau, The Compromises of Printing Organic Electronics: A Case Study of Gravure-Printed Light-Emitting Electrochemical Cells. Advanced Materials, 2014. 26(20): p. 3235-3240.

43. L. Hakola, E. Jansson, S. Rousu, and R. Suhonen, Optimizing the Performance of Metal Grid Conductors for Light-Emitting Electrochemical Cell Devices by Modifying Printing Conditions. Journal of Imaging Science and Technology, 2014. 58(3): p. 10.

44. D. Tordera, J. Frey, D. Vonlanthen, E. Constable, A. Pertegás, E. Ortí, H.J. Bolink, E. Baranoff, and M.K. Nazeeruddin, Low Current Density Driving Leads to Efficient, Bright and Stable Green Electroluminescence. Advanced Energy Materials, 2013. 3(10): p. 1338-1343.

45. N.M. Shavaleev, R. Scopelliti, M. Gratzel, M.K. Nazeeruddin, A. Pertegas, C. RoldanCarmona, D. Tordera, and H.J. Bolink, Pulsed-current versus constant-voltage lightemitting electrochemical cells with trifluoromethyl-substituted cationic iridium(iii) complexes. Journal of Materials Chemistry C, 2013. 1(11): p. 2241-2248.

46. G. Yu, Y. Cao, C. Zhang, Y. Li, J. Gao, and A.J. Heeger, Complex admittance measurements of polymer light-emitting electrochemical cells: Ionic and electronic contributions. Applied Physics Letters, 1998. 73(1): p. 111-113.

47. J.F. Fang, P. Matyba, and L. Edman, The Design and Realization of Flexible, LongLived Light-Emitting Electrochemical Cells. Advanced Functional Materials, 2009. 19(16): p. 2671-2676.

48. X.Y. Li, F. AlTal, G.J. Liu, and J. Gao, Long-term, intermittent testing of sandwich polymer light-emitting electrochemical cells. Applied Physics Letters, 2013. 103(24).

49. S. van Reenen, R.A.J. Janssen, and M. Kemerink, Fundamental Tradeoff between Emission Intensity and Efficiency in Light-Emitting Electrochemical Cells. Advanced Functional Materials, 2015. 25(20): p. 3066-3073.

50. J. Gao and F. AlTal, Decoupled luminance decay and voltage drift in polymer lightemitting electrochemical cells: Forward bias vs. reverse bias operation. Applied Physics Letters, 2014. 104(14): p. 143301.

51. J. Fang, P. Matyba, N.D. Robinson, and L. Edman, Identifying and alleviating electrochemical side-reactions in light-emitting electrochemical cells. J Am Chem Soc, 2008. 130(13): p. 4562-8.

52. J.H. Shin, P. Matyba, N.D. Robinson, and L. Edman, The influence of electrodes on the performance of light-emitting electrochemical cells. Electrochimica Acta, 2007. 52(23): p. 6456-6462.

53. D.A. Bernards, J.D. Slinker, G.G. Malliaras, S. Flores-Torres, and H.c.D. Abruña, Cascaded light-emitting devices based on a ruthenium complex. Applied Physics Letters, 2004. 84(24): p. 4980.

54. J.D. Slinker, J. Rivnay, J.A. DeFranco, D.A. Bernards, A.A. Gorodetsky, S.T. Parker, M.P. Cox, R. Rohl, G.G. Malliaras, S. Flores-Torres, and H.c.D. Abruña, Direct 120 $\mathrm{V}, 60 \mathrm{~Hz}$ operation of an organic light emitting device. Journal of Applied Physics, 2006. 99(7): p. 074502. 


\title{
Supporting Information
}

\section{Design, Fabrication and Application of Organic Power Converters: Driving Light-emitting Electrochemical Cells from the AC Mains}

\author{
Christian Larsen, Robert Forchheimer, Ludvig Edman* and Deyu Tu*
}

Dr. C. Larsen and Prof. L. Edman

Department of Physics, Umeå University, SE-901 87 Umeå, Sweden

Prof. R. Forchheimer and Dr. D. Tu

Department of Electrical Engineering, Linköping University, SE-581 83 Linköping, Sweden

E-mail: L.E. (ludvig.edman@umu.se) and D.T. (deyu@isy.liu.se)

A source-drain current of 850-950 $\mu \mathrm{A}$ was typically measured for non-encapsulated OFET devices operating at $V_{G S}=V_{D S}=-200 \mathrm{~V}$. The current dropped to $700-800 \mu \mathrm{A}$ after encapsulation. With $\varepsilon_{\mathrm{r}}=3.8$ for PMMA, a mobility can be extracted from the measured data. The data for the hole mobility $\left(\mu_{\mathrm{h}}\right)$ and the threshold voltage $\left(V_{\mathrm{T}}\right)$ are shown in table S1. 16 randomly selected devices were measured from a total of 48 before encapsulation and another 16 were randomly measured after encapsulation.

Table S1. Hole mobility and threshold voltage extracted from I-V measurements on encapsulated and non-encapsulated devices. The presented values are means with standard deviation in parenthesis.

\begin{tabular}{clc} 
Device & $\boldsymbol{\mu}_{\mathrm{h}}\left[\mathrm{cm}^{2} \mathrm{~V}^{-1} \mathrm{~s}^{-1}\right]$ & $\boldsymbol{V}_{\mathrm{T}}[\mathrm{V}]$ \\
\hline Encapsulated & $2.6( \pm 0.1) \times 10^{-2}$ & $1.7( \pm 2.3)$ \\
\hline Non-encapsulated & $2.8( \pm 0.1) \times 10^{-2}$ & $3.1( \pm 1.5)$ \\
\hline
\end{tabular}

The devices exhibit a positive, albeit low, $V_{\mathrm{T}}$. The low $V_{\mathrm{T}}$ indicates a low density of trap states at the PMMA/P3HT interface, but, as the consequence, an IDs between 1-2 $\mu \mathrm{A}$ is measured through the device at $V_{G S}=0 \mathrm{~V}$. 

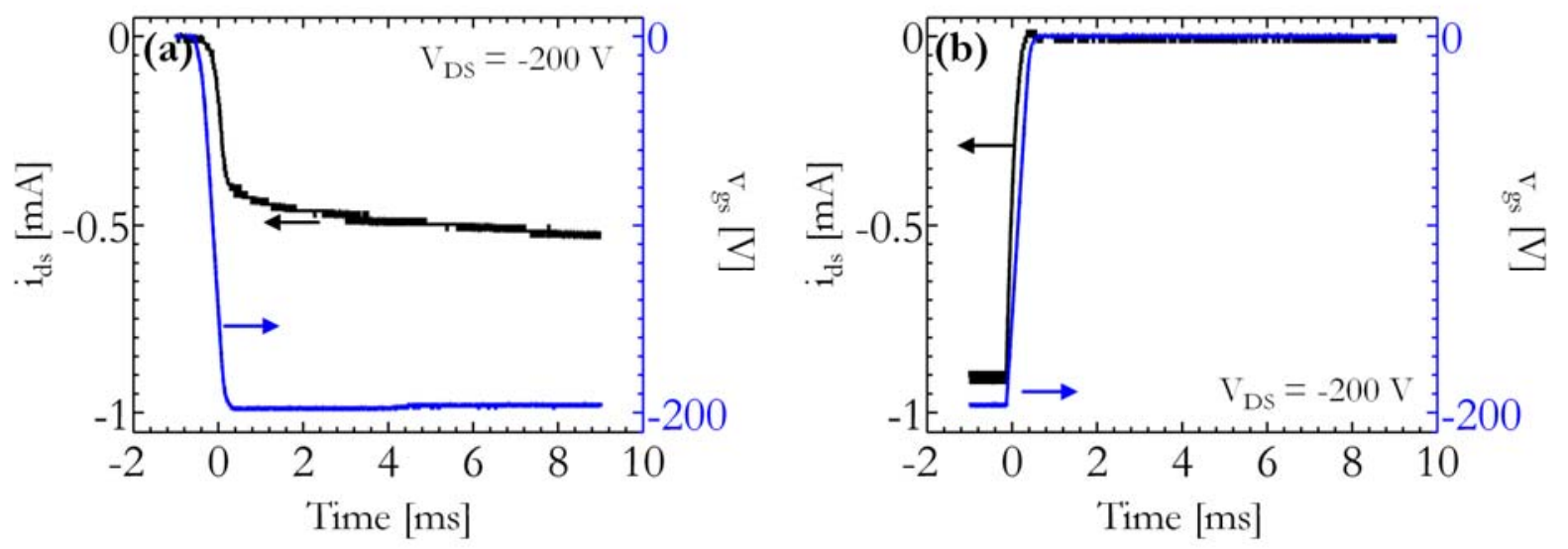

Figure S1. Temporal measurements on a 3-terminal high-voltage OFET showing the $i_{d s}$ (black lines, left axis) pulsed between $0 \mathrm{~V}$ and $-200 \mathrm{~V}$ using a step input $\mathrm{v}_{\text {gs }}$ (blue lines, right axis). (a) A rise-time of $0.7 \mathrm{~ms}$ and (b) a fall-time of $0.1 \mathrm{~ms}$ is measured, indicating that operation at 50 $\mathrm{Hz}$ (as needed for the AC-to-DC converter) is possible. $V_{D S}=-200 \mathrm{~V}$ in this measurement. Riseand fall-times are determined where $i_{d s}$ have reached $50 \%$ of the final height.

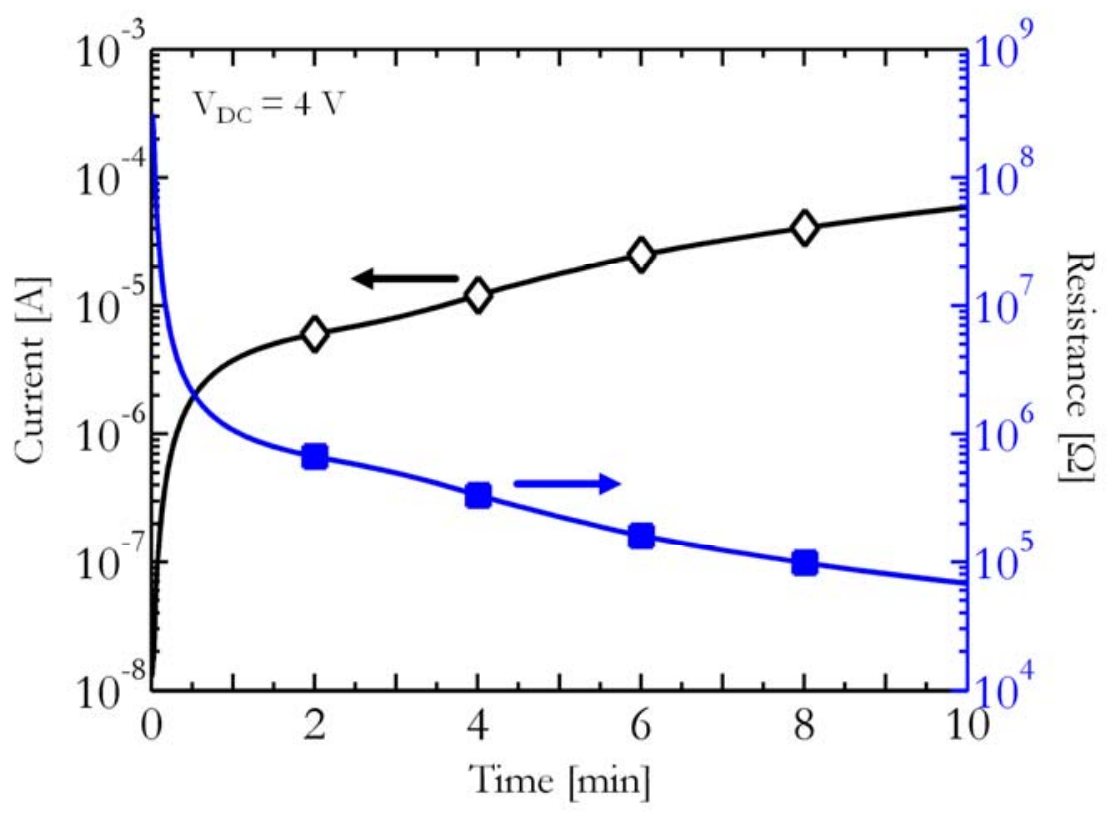

Figure S2. Typical turn-on temporal current (black open diamonds, left axis) and resistance (blue solid squares, right axis) of a $2 \times 2 \mathrm{~mm}^{2}$ LEC device when powered with a constant voltage $V_{D C}=4 \mathrm{~V}$. The current density varies over several orders of magnitude within the first few minutes, varying from the initial $\sim 10 \mathrm{nA}(400 \mathrm{M} \Omega)$ at $t=0$ to $\sim 60 \mu \mathrm{A}(67 \mathrm{k} \Omega)$ at $t=10$ $\min$. 

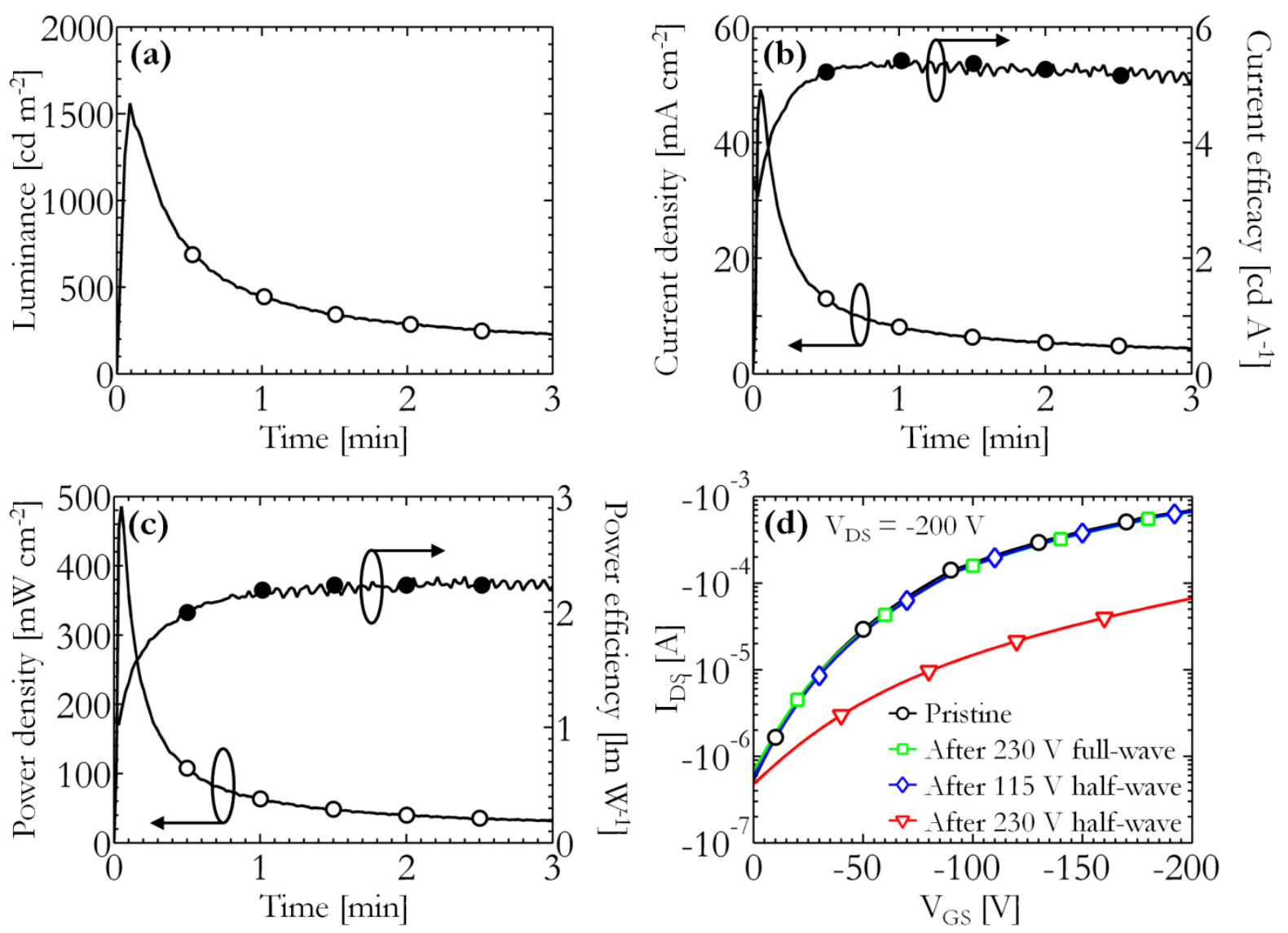

Figure S3. (a-c) The temporal LEC performance during pulsed operation ( $C=0 \mu F)$ with a halfwave converter at $V_{A C}=230 \mathrm{~V}, f=50 \mathrm{~Hz}$. (d) The transfer data of the 3-terminal high-voltage OFETs used in the rectifiers. The black circles corresponds the pristine behavior prior to testing. The green squares and the blue diamonds correspond to the unchanged performance after $10 \mathrm{~h}$ of $V_{A C}=230 \mathrm{~V}$ full-wave operation and after $V_{A C}=115 \mathrm{~V}$ half-wave operation, respectively. The red triangles corresponds to the degraded performance following the short $(<5 \mathrm{~min}) V_{A C}=230 \mathrm{~V}$ half-wave operation. 